\title{
Saccharin Sulfonic Acid as an Efficient Catalyst for the Preparation and Deprotection of 1,1-Diacetates
}

\author{
F. Shirini, ${ }^{*}$ M. Mamaghani, T. Mostashari-Rad, and M. Abedini \\ Department of Chemistry, College of Science, University of Guilan, Rasht-Iran. *E-mail: shirini@guilan.ac.ir \\ Received May 30, 2010, Accepted June 24, 2010
}

Key Words: Saccharin sulfonic acid, Aldehydes, 1,1-Diacetates, Protection, Deprotection

The Protection and deprotection of organic functional groups are important procceses during multi-step organic synthesis. ${ }^{1}$ The choice of a method which is used for the functional group transformations depends on its simplicity, high yields of the desired products, short reaction times, low cost of the process and ease of the work-up procedure.

Between the several methods available for the protection of aldehydes, acylal formation is often preferred due to the ease of preparation and the stability of the produced 1,1-diacetate towards basic and neutral conditions. ${ }^{1,2}$ In addition, 1,1-diacetates serve as valuable precursors for asymmetric allylic alkylation $^{3}$ and synthesis of natural products ${ }^{4}$ as well as for the synthesis of 1-acetoxydienes and 2,2-dichlorovinylacetates for Diels-Alder reactions. ${ }^{5,6}$ Acylals have also been used as crosslinking agents for cellulose in cotton and as bleaching activators in wine-stained fabrics. ${ }^{7,8}$ Moreover, the acylal functionality can be converted to other functional groups by reaction with appropriate nucleophiles. ${ }^{9,10}$ A variety of methods for the preparation of acylals from aldehydes and acetic anhydride have been reported. ${ }^{11-24}$ Although some of these methods offered to high yields of the corresponding diacetates, the major disadvantages are: long reaction times, harsh reaction conditions, use

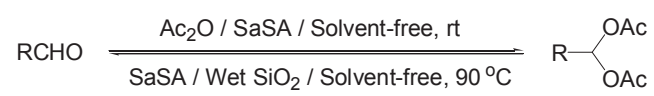

Scheme 1

of strong acids, low yields, strictly reaction conditions, moisture sensitivity as well as high cost and high toxicity of the reagents and special efforts required to prepare the catalyst. Thus, the search for new reagents and methods is still of practical importance.

Recently and in continuation of our ongoing research program on the development of new methods for the functional group transformations, ${ }^{25-28}$ we have reported the preparation of saccharin sulfonic acid (SaSA) and its application in the chemoselective trimethylsilylation of alcohols and acetylation of alcohols, phenols and amines. ${ }^{29,30}$ Our investigation clarified that saccharin sulfonic acid is also a suitable catalyst for the efficient conversion of aldehydes to their corresponding 1,1-diacetates with acetic anhydride. All reactions were performed in the absence of solvent at room temperature producing the desired products in good to high yields (Scheme 1).

The reaction yields and times are given in Table 1. Benzylic aldehydes, including different substituents such as $\mathrm{Cl}, \mathrm{Br}, \mathrm{CN}$, $\mathrm{NO}_{2}$ and $\mathrm{OMe}$ are converted to their corresponding acylals in good to high yields (Table 1, entries 1-15). This method is also very useful for the protection of aliphatic aldehydes (Table 1, entries 16, 17). Ketones are so stable under the same reaction conditions, that the starting material was recovered unchanged after $3 \mathrm{~h}$ (Table 1, entry 18). Therefore, the method can be useful for the chemoselective acylation of aldehydes in the presence of ketones. This is exemplified by the competitive reaction between 3-methylbenzaldehyde and acetophenone (Table 1, entry 19).

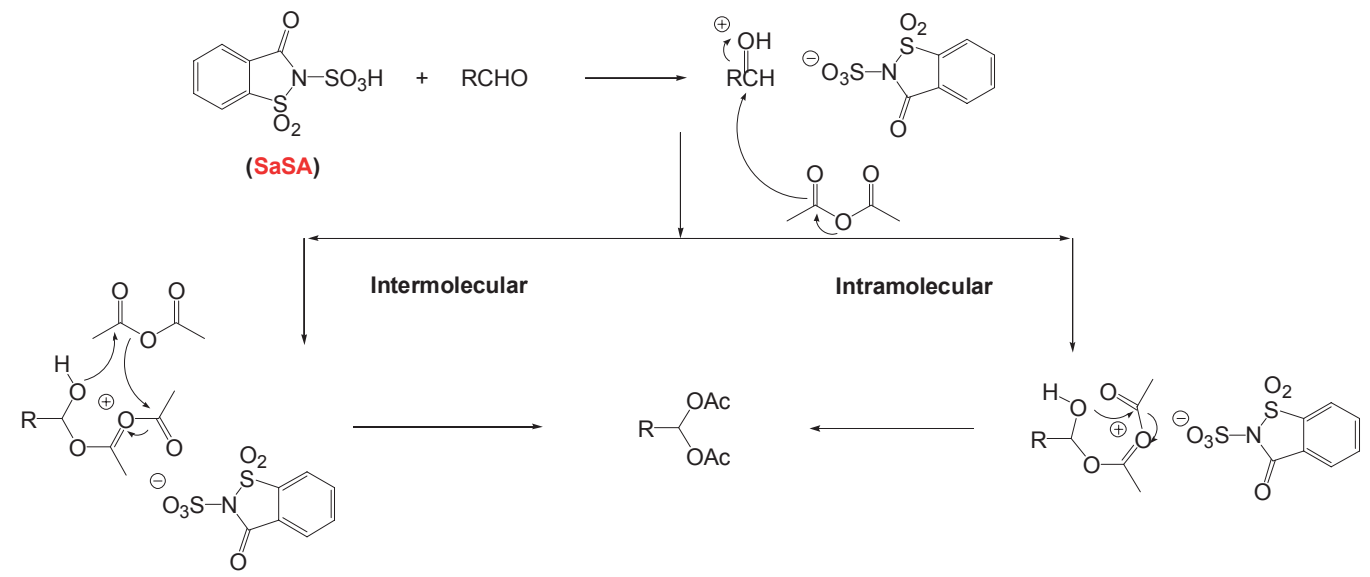

Scheme 2. Two plausible reaction mechanisms for the formation of 1,1-diacetates 
Table 1. Acylation of aldehydes and deprotection of obtained acylals. ${ }^{a, b}$

\begin{tabular}{|c|c|c|c|c|c|}
\hline \multirow[b]{2}{*}{ Entry } & \multirow[b]{2}{*}{ Substrate } & \multicolumn{2}{|c|}{ Protection } & \multicolumn{2}{|c|}{ Deprotection } \\
\hline & & $\begin{array}{c}\text { Time } \\
\text { (h) }\end{array}$ & $\begin{array}{c}\text { Yield } \\
(\%)\end{array}$ & $\begin{array}{l}\text { Time } \\
(\mathrm{min})\end{array}$ & $\begin{array}{c}\text { Yield } \\
(\%)\end{array}$ \\
\hline 1 & $\mathrm{PhCHO}$ & 0.8 & 90 & 2 & 95 \\
\hline 2 & $2-\mathrm{ClC}_{6} \mathrm{H}_{4} \mathrm{CHO}$ & 2 & 85 & 5 & 90 \\
\hline 3 & $3-\mathrm{ClC}_{6} \mathrm{H}_{4} \mathrm{CHO}$ & 1 & 90 & 10 & 90 \\
\hline 4 & 4- $\mathrm{ClC}_{6} \mathrm{H}_{4} \mathrm{CHO}$ & 1 & 92 & 5 & 87 \\
\hline 5 & $4-\mathrm{BrC}_{6} \mathrm{H}_{4} \mathrm{CHO}$ & 1 & 95 & 5 & 92 \\
\hline 6 & $2-\mathrm{NO}_{2} \mathrm{C}_{6} \mathrm{H}_{4} \mathrm{CHO}$ & 4 & 92 & 3 & 90 \\
\hline 7 & $4-\mathrm{NO}_{2} \mathrm{C}_{6} \mathrm{H}_{4} \mathrm{CHO}$ & 3 & 92 & 3 & 95 \\
\hline 8 & 4- $\mathrm{CNC}_{6} \mathrm{H}_{4} \mathrm{CHO}$ & 4 & 80 & 30 & 92 \\
\hline 9 & $2-\mathrm{MeC}_{6} \mathrm{H}_{4} \mathrm{CHO}$ & 1 & 95 & 4 & 90 \\
\hline 10 & $3-\mathrm{MeC}_{6} \mathrm{H}_{4} \mathrm{CHO}$ & 1 & 92 & 3 & 90 \\
\hline 11 & 4- $\mathrm{MeC}_{6} \mathrm{H}_{4} \mathrm{CHO}$ & 0.75 & 92 & 2 & 95 \\
\hline 12 & 4- $\mathrm{Me}_{2} \mathrm{CHC}_{6} \mathrm{H}_{4} \mathrm{CHO}$ & 1 & 85 & 2 & 90 \\
\hline 13 & $3-\mathrm{MeOC}_{6} \mathrm{H}_{4} \mathrm{CHO}$ & 1.5 & 88 & 1 & 90 \\
\hline 14 & 2-Naphthaldehyde & 1.5 & 90 & 6 & 85 \\
\hline 15 & Furfural & 1.5 & 75 & 15 & 90 \\
\hline 16 & $\mathrm{PhCH}_{2} \mathrm{CH}_{2} \mathrm{CHO}$ & 0.5 & 90 & 30 & 90 \\
\hline 17 & $\mathrm{PhCH}(\mathrm{Me}) \mathrm{CHO}$ & 1.7 & 90 & 30 & 92 \\
\hline 18 & $\mathrm{PhCOMe}$ & 1 & $0^{c}$ & - & - \\
\hline 19 & $\begin{array}{c}3-\mathrm{MeC}_{6} \mathrm{H}_{4} \mathrm{CHO} \\
+ \\
\mathrm{PhCOMe}\end{array}$ & 1 & $\begin{array}{c}100^{d} \\
+ \\
0^{d}\end{array}$ & - & - \\
\hline
\end{tabular}

${ }^{a}$ Products were identified spectroscopically. ${ }^{b}$ Isolated yields. ${ }^{c}$ Starting material recovered intact. ${ }^{d}$ Conversion.

Although the actual role of SaSA is not clear, the proposed mechanism that is shown in Scheme 2 can be selected as the most probable one.

Our investigations clarified that the deprotection of 1,1-diacetates can also be easily catalyzed in the presence of a mixture of SaSA and wet $\mathrm{SiO}_{2}$. All reactions were performed in the absence of solvent at $90{ }^{\circ} \mathrm{C}$ in good to high yields (Table 1, Scheme 1).

In conclusion, saccharin sulfonic acid can be used as an efficient catalyst for the acylation of aldehydes using acetic anhydride. This is also a suitable catalyst for the regeneration of aldehydes from the related acylals in the presence of wet $\mathrm{SiO}_{2}$. The significant advantages of this methodology are mild, solvent-free reaction conditions, relatively short reaction times, high yields of the products, selectivity and easy work-up.

\section{Experimental}

General. Chemicals were purchased from Fluka, Merck and Aldrich. Products were separated and purified by different chromatographic techniques and were identified by the comparison of their IR and NMR with those reported for the authentic samples. All yields refer to the isolated products. The purity of the substrate and reaction monitors were accompanied with TLC on Silica-gel polygram SILG/UV 254 plates.

General procedure for acylation of aldehydes: Aldehyde
( $1 \mathrm{mmol})$, acetic anhydride $(3 \mathrm{mmol})$, and SaSA (0.2 mmol, $0.05 \mathrm{~g}$ ) were added in a flask and stirred for the appropriate time (Table 1). The reaction was monitored by TLC. On completion, $\mathrm{CH}_{2} \mathrm{Cl}_{2}(5 \mathrm{~mL})$ was added and the reaction mixture was filtered and the solid residue was washed with $\mathrm{CH}_{2} \mathrm{Cl}_{2}(5 \mathrm{~mL})$. The organic layer was washed with $5 \%$ solution of $\mathrm{NaHCO}_{3}$ (aq), and water and dried over $\mathrm{MgSO}_{4}$. Evaporation of the solvent followed by column chromatography on silica gel afforded the pure corresponding 1,1-diacete.

General procedure for deprotection of 1,1-diacetates: A mixture of 1,1-diacetate ( $1 \mathrm{mmol}), \operatorname{SaSA}(0.1 \mathrm{mmol}, 0.025 \mathrm{~g})$ and wet $\mathrm{SiO}_{2}(50 \% \mathrm{w} / \mathrm{w}, 0.1 \mathrm{~g})$ was heated in an oil bath $\left(90^{\circ} \mathrm{C}\right)$ for the appropriate time (Table 1). On completion, $\mathrm{CH}_{2} \mathrm{Cl}_{2}(5 \mathrm{~mL})$ was added and the reaction mixture was filtered and the solid residue was washed with $\mathrm{CH}_{2} \mathrm{Cl}_{2}(5 \mathrm{~mL})$. The organic layer was washed with $5 \%$ solution of $\mathrm{NaHCO}_{3}(\mathrm{aq})$, and water and dried over $\mathrm{MgSO}_{4}$. Evaporation of the solvent followed by column chromatography on silica gel afforded the pure corresponding aldehyde.

Acknowledgments. We are thankful to the University of Guilan Research Council for the partial support of this work.

\section{References}

1. Greene, T. W.; Wuts, P. G. M. Greene's Protective Groups in Organic Synthesis, 4th ed.; Wiley: New York, 2007.

2. Kochhar, K. S.; Bal, B. S.; Deshpande, R. P.; Rajadhyaksha, S. N.; Pinnick, H. W. J. Org. Chem. 1983, 48, 1765.

3. Trost, B. M.; Lee, C. J. Am. Chem. Soc. 2001, 123, 12191.

4. Sandberg, M.; Sydnes, L. K. Org. Lett. 2000, 2, 687.

5. Held, H.; Rengestle, A.; Mayer, A. In Ullman's Encyclopedia of Industrial Chemistry, 5 th ed.; Gerhartz, W., Ed.; Wiley-VCH: New York, 1985; Vol. 1.

6. Freeman, F.; Karchefski, E. M. J. Chem. Eng. Data 1977, 22, 355.

7. Frick, J. G., Jr. ; Harper, R. J., Jr. J. Appl. Polym. Sci. 1984, 29, 1433.

8. Eanderson, W. R. Eur. Pat. Appl. 1985, EP 125 781; Chem. Abstr. 1985, 102, P64010K.

9. Van Heerden, F. R.; Huyser, J. J.; Bradley, D.; Williams, G.; Holzapfel, C. W. Tetrahedron Lett. 1988, 39, 5281.

10. Sandberg, M.; Sydnes, L. K. Tetrahedron Lett. 1998, 39, 6361.

11. Manjula, K.; Afzal Pasha, M. Synth. Commun. 2007, 37, 1563.

12. Desai, U. V.; Thopate, T. S.; Pore, D. M.; Wadgaonkar, P. P. Catal. Commun. 2006, 7, 508.

13. Wang, M.; Gong, H.; Jiang, H.; Wang, Z. Synth. Commun. 2006, 36, 1953.

14. Gregory, M. J. J. Chem. Soc. B 1970, 1201.

15. Firouzabadi, H.; Iranpoor, N.; Nowrouzi, F.; Amani, K. Tetrahedron Lett. 2003, 44, 3951.

16. Nagy, N. M.; Jakab, M. A.; Konya, J.; Antus, S. Appl. Clay Sci. 2002, 21, 213.

17. Smitha, G.; Reddy, C. S. Tetrahedron 2003, 59, 9571.

18. Wang, J.; Yan, L.; Qian, G.; Yang, K.; Liu, H.; Wang, X. Tetrahedron Lett. 2006, 47, 8309.

19. Kumar, R.; Tiwari, P.; Maulik, P. R.; Misra, A. K. J. Mol. Catal. A: Chem. 2006, 247, 27.

20. Jeyakumar, K.; Chand, D. K. J. Mol. Catal. A: Chem. 2006, 255, 275.

21. Wang, M.; Song, Z.; Gong, H.; Jiang, H. Synth. Commun. 2008, 38,961

22. Saini, A.; Kumar, S.; Sandhu, J. S. Synth. Commun. 2008, 38, 106. 
23. Khan, A. T.; Choudhury, L. H.; Ghosh, S. J. Mol. Catal. A: Chem. 2006, 255, 230.

24. Aggen, D. H.; Arnold, J. N.; Hayes, P. D.; Smoter, N. J.; Mohan, R. S. Tetrahedron 2004, 60, 3675.

25. Kolvari, E.; Ghorbani-Choghamarani, A.; Salehi, P.; Shirini, F.; Zolfigol, M. A. J. Iran. Chem. Soc. 2007, 2, 126.

26. Shirini, F.; Zolfigol, M. A.; Salehi, P.; Abedini, M. Current Org. Chem. 2008, 12, 183.
27. Shirini, F.; Abedini, M.; Ghasemi, M.; Sakhaei, A. R. Bull. Korean Chem. Soc. 2009, 10, 2479.

28. Shirini, F.; Zolfigol, M. A.; Albadi, J. Synth. Commun. 2010, 40, 910.

29. Shirini, F.; Zolfigol, M. A.; Abedini, M. Monatsh. Chem. 2009, 140,61 .

30. Shirini, F.; Zolfigol, M. A.; Abedini, M. Monatsh. Chem. 2009, 140, 1495. 